\title{
Refining memory assessment of elderly people with cognitive impairment: insights from the short-term memory binding test
}

Mario A Parra ${ }^{1-4}$, Clara Calia ${ }^{5}$, Ana Frank García ${ }^{6}$, Javier Olazarán-Rodríguez ${ }^{7}$, Juan Antonio Hernandez-Tamames ${ }^{8}$, Juan Alvarez-Linera ${ }^{9}$, Sergio Della Sala ${ }^{4}$, and Sara Fernandez Guinea ${ }^{10}$

${ }^{1}$ School of Psychological Sciences and Health, Department of Psychology, University of Strathclyde, Glasgow, UK.

${ }^{2}$ Universidad Autónoma del Caribe, Barranquilla, Colombia.

${ }^{3}$ Alzheimer Scotland Dementia Research Centre and Neuroprogressive and Dementia Network, $U K$.

${ }^{4}$ Human Cognitive Neuroscience and Centre for Cognitive Ageing and Cognitive Epidemiology, Department of Psychology, University of Edinburgh, UK.

${ }^{5}$ School of Health in Social Science, University of Edinburgh. UK

${ }^{6}$ Neurology Department, University Hospital la Paz, Madrid, Spain.

${ }^{7}$ Neurology Department, University Hospital Gregorio Marañón, Madrid, Spain.

${ }^{8}$ Magnetic Resonance Physics Group. Radiology and Nuclear Medicine Department, Erasmus MC, Rotterdam, The Netherlands.

${ }^{9}$ Neuroradiology Department. Hospital Ruber Internacional, Madrid, Spain

${ }^{10}$ Department of Basic Psychology II (Cognitive Processes), Faculty of Psychology, Complutense University of Madrid, Spain. 
Corresponding author: Dr Mario A Parra, chool of Psychological Sciences and Health, Department of Psychology, University of Strathclyde, Graham Hills Building, 40 George Street, Glasgow, G1 1QE. mario.parra-rodriguez@strath.ac.uk

Short Title: Visual Short-Term Memory Binding in Prodromal AD

\begin{abstract}
Alzheimer's disease (AD) affects temporary memory for bound features more remarkably than for individual features. Such selective impairments manifest from presymptomatic through dementia stages via titration procedures. A recent study suggested that without titration and with high memory load the binding selectivity may disappear in people at risk of AD such as those with Mild Cognitive Impairment (MCI). We compared data from two studies on temporary binding which assessed people with MCI and controls using different memory loads (2 or 3 items). Selective binding impairments were found in MCI, but relative to controls, such selectivity was contingent upon memory load (i.e., present with 2 items). Further analysis with MCI people who tested positive to neuroimaging biomarkers (i.e., hippocampal atrophy) confirmed that this specific binding impairments are a feature of prodromal AD. The temporary binding task has been recently suggested by consensus papers as a potential screening tool for AD. The results presented here inform on task properties that can maximise the reliability of this new assessment tool for the detection of memory impairments in prodromal cases of AD.
\end{abstract}

Keywords: Short-term memory binding; Mild Cognitive Impairment; prodromal Alzheimer's disease; Neuropsychological assessment; Early detection 


\section{Introduction}

Memory assessment in individuals at risk of Alzheimer's disease (AD), such as those with Mild Cognitive Impairment (MCI), has long focused on episodic memory functions (Fields, Ferman, Boeve, \& Smith, 2011; Parra, Abrahams, Logie, Mendez, et al., 2010; Parra et al., 2011). Examples are Paired Associates Learning (PAL) tasks (Sahakian et al., 1988), the Face Name Associative Memory Exam (FNAME) (Amariglio et al., 2012; Rentz et al., 2013), the Free and Cued Selective Reminding test (FCSRT) (E. Barbeau et al., 2004; Buschke, 2014; Grober, Buschke, Crystal, Bang, \& Dresner, 1988; Sarazin et al., 2007), and other episodic memory tests (Ivanoiu et al., 2005). These tests are known to assess functions of the hippocampus which are essential to episodic memory formation i.e., associative memory (Tulving, 2002). Tests assessing associative memory functions of the hippocampus are considered markers for AD (Auriacombe et al., 2010; E. J. Barbeau et al., 2008; Dubois et al., 2010; Rentz et al., 2013; Sarazin et al., 2007). To uphold the claim that the associative function is that selectively impaired in $\mathrm{AD}$, it is necessary to demonstrate that such impairments are greater than those found when patients remember the individual items. For instance, memory for faces (Sperling et al., 2003), lists of words (Gallo, Sullivan, Daffner, Schacter, \& Budson, 2004), or locations (Stehli, Chubb, \& Jacob, 2003), are functions affected by AD. This makes it difficult to ascertain that holding associations between these items in memory (e.g., faces and locations, faces and names) is the hallmark of AD. This is important because item memory and associative memory dissociate (Chalfonte, Verfaellie, Johnson, \& Reiss, 1996; Old \& Naveh-Benjamin, 2008) and the form of representation claimed to be specifically affected by the hippocampal amnesia of AD is the latter. This caveat i.e., limited underlying constructs, has been recently highlighted by a recent consensus paper (Costa et al., 2017). 
The Visual Short-Term Memory Binding Test (VSTMBT) was developed to investigate if the function responsible for binding features within object representations is affected by $\mathrm{AD}$ above and beyond that supporting single feature processing (Parra, Abrahams, Logie, \& Della Sala, 2010). The test assesses participants' memory for single features such as shapes and for combination of features such as shape-colour bindings. When memory load is controlled for (i.e., via titration to keep patients' and controls' memory performance for individual features at the same level), patients with AD show memory binding deficits which are far greater than those found when memory for single features is assessed (S. Della Sala, Parra, Fabi, Luzzi, \& Abrahams, 2012; Parra et al., 2009; Parra, Abrahams, Logie, \& Della Sala, 2010; Parra, Abrahams, Logie, Mendez, et al., 2010; Parra et al., 2011). Such specific increase of the cost of binding has been observed since the preclinical stages of $\mathrm{AD}$. This fits well current trends in the assessment of $\mathrm{AD}$ which have shifted towards a new lexicon (Costa et al., 2017; Dubois et al., 2010; Dubois et al., 2016) that encourages the detection of subtle cognitive impairments in stages prior to dementia. The VSTMBT detects such early impairments, even when other novel and traditional tests have failed (Parra, Abrahams, Logie, Mendez, et al., 2010; Parra et al., 2011).

The results form a recent study (Koppara et al., 2015) suggest that memory load may be a factor precluding the specificity of the VSTMBT (i.e., greater cost of binding in patients than in controls). Previous studies have manipulated memory load by presenting patients and controls with a different number of to-be-remembered items (Sergio Della Sala, Data, Stamate, \& Parra, 2017; S. Della Sala et al., 2012; Parra et al., 2009; Parra, Abrahams, Logie, \& Della Sala, 2010; Parra, Abrahams, Logie, Mendez, et al., 2010; Parra et al., 2011). Such manipulation rested on the assumption that VSTM stores a limited number of items (Luck \& Vogel, 1997; Vogel, Woodman, \& Luck, 2001) and that increasing the number of items above such a limit (i.e., 4) would overload 
memory, rendering the task more challenging and performance poorer. Titration aimed at reducing differences at baseline (i.e., memory for single features). This led to suggesting that patients with AD present with a selective deficit of VSTMB. (Koppara et al., 2015) showed that without titration (i.e., patients and controls tested with the same visual arrays of 3 items), the selectivity of the VSTMBT holds for people with Subjective Cognitive Deficits (SCD) but not for people with MCI. Considering that memory binding is maintained to be selectively impaired in $\mathrm{AD}$ and that $\mathrm{MCI}$ is an uncertain clinical category which holds limited value to predict future risk of dementia, it is important to demonstrate the precise testing conditions with which selective impairments of VSTMB can be found. Is the specific impaired ability to binding features in VSTM that has been considered a hallmark of AD. Hence, identifying such a hallmark in MCI people might provide more reliable evidence of $\mathrm{AD}$ pathology as the likely underlying mechanism. To address these outstanding issues, in the present paper we present data from groups of healthy older adults and people with MCI who were assessed with the VSTMBT using arrays of 2 and 3 items and without titration. If the above-mentioned selectivity is contingent upon memory load, it would be observed only under the low memory load condition (i.e., 2 items).

\section{Methods}

\section{Participants}

Participants came from two separate samples of people with MCI and matched controls assessed with different versions of the VSTMBT. One sample was tested with a version of the task presenting 2 items, the other sample was assessed with a version presenting 3 items. Table 1 shows the demographic, clinical and neuropsychological variables of the participants tested with the two set sizes. All participants underwent neuropsychological assessment. People with MCI met criteria 
proposed by (Petersen, 2004). Participants were fully informed about the study and they signed an Informed Consent Form prior to participation. The study was approved by Ethics Committees from the Psychology Faculty, Complutense University of Madrid, Clinical University Hospital San Carlos from Madrid, and the University Hospital Gregorio Marañón also from Madrid.

\section{The Visual Short-Term Memory Binding Test (VSTMBT)}

The VSTMBT required participants to remember visual arrays in which two or three black shapes (Shape Only condition) or coloured shapes (Shape-Colour Binding Condition) were presented for 2 seconds (Figure 1A). After a brief delay (1 second), a test display appeared showing the same or different items all presented in new random locations. The task was to indicate verbally whether the study and test display showed the same (50\% of the trials) or different items. Different trials in the Shape Only condition presented two new shapes at test. Different trials in the Shape-Colour Binding condition presented two re-arranged combinations of shape and colour (i.e., two shapes swapped their colours at test). Normal perception of shape-colour bindings was ensued prior to the VSTMBT. Each condition presented 32 trials in random order. Conditions were counterbalanced across participants. We calculated proportion of correct recognition (see (Parra, Abrahams, Logie, \& Della Sala, 2010), for a detailed description of the task). The above described VSTMBT has been used extensively in experimental studies involving different populations with $\mathrm{AD}$ dementia or at risk of such dementia. More clinically friendly versions of the task (i.e., shorter version on PC or flashcard versions; see (Della Sala, et al., 2017)) have been recently developed and validated. Using these clinical versions of the test, patients with $\mathrm{AD}$ dementia and controls were discriminated via ROC analyses with $100 \%$ sensitivity and specificity. These versions of the test are available for use on request (contact corresponding author). 


\section{Analysis}

A mixed ANOVA model was used with Group (Controls Set Size 2 vs. people with MCI Set Size

2 vs. Controls Set Size 3 vs. people with MCI Set Size 3) as the between-subjects factor and Condition (Shape Only vs. Shape-Colour Binding) as the within-subjects factor. We calculated effect size and power for main effects and interactions.

\section{Results}

The groups were matched on age, education, and depression scores. People with MCI showed a profile compatible with the multi-domain amnestic stage. The two groups of people with MCI showed a very similar profile of cognitive impairments. Control groups from the two samples did not differ in any of the neuropsychological scores (see Table 1).

Insert Table 1 about here

The ANOVA model revealed a main effect of Group $\left[F(3,100)=24.9, \mathrm{p}<0.001, \eta^{2}=0.43 ; \beta=1.0\right]$, main effect of Condition $\left[F(1,100)=187.14, \mathrm{p}<0.001, \eta^{2}=0.65 ; \beta=1.0\right]$, and a significant Group $\mathrm{x}$ Condition Interaction $\left[F(3,100)=6.93, \mathrm{p}<0.001, \eta^{2}=0.17 ; \beta=0.97\right]$ (Figure 2). To unfold this 
interaction we ran two separate Group x Condition ANOVAs for each Set Size. For Set Size 3 the interaction was non-significant $\left[F(1,50)=2.91, \mathrm{p}=0.094, \eta^{2}=0.05 ; \beta=0.39\right]$, because of a large drop in binding performance in controls. For Set Size 2 it was significant $[F(1,50)=14.86, \mathrm{p}<0.001$, $\left.\eta^{2}=0.23 ; \beta=0.79\right]$. Post-hoc analysis (Table 1 ) revealed that MCI people's performance on the Shape-Colour Binding condition was disproportionally lower than that on the Shape Only condition, a discrepancy not observed in controls. Although these results are appealing, they may still face limitations for diagnosis purposes as having MCI and VSTMB deficits may not unequivocally inform about the presence of prodromal $\mathrm{AD}$. We ran further analyses using neuroimaging data to investigate if such a pattern of selective impairment holds for those who are considered biomarker positive (Dubois et al., 2010; Dubois et al., 2016).

\section{Additional Analysis}

A subsample of 17 people with MCI who were assessed with set size 2 underwent MRI scans. The volume of their hippocampus was measured and corrected for their intracranial volume. Individual hippocampal atrophy was assessed using voxel-based morphometry, as described in (Olazaran et al., 2013). Hippocampal volume measurements were calculated using the freely available software FreeSurfer (http://surfer.nmr.mgh.harvard.edu/). We used automatic subcortical segmentation based upon the existence of an atlas containing probabilistic information on the location of structures. We followed the procedures described by Fischl (Fischl et al., 2002). The accuracy of FreeSurfer results was then assessed visually for the different participants (Olazaran et al., 2013). The extracted volumes were corrected for the total Intra-cranial Volume (ICV). The cut-off to identify pathological atrophy was set at -1SD from controls (see Supplementary Figure 1; see also 
(Jack et al., 1997)). According to these data, 10 participants with MCI show hippocampal atrophy (MTA) beyond that expected for their age (-1SD below the control group, see Supplementary

Figure 1). We ran additional analyses with the VSTMB data collected from this subsample of MCI+MTA using the model described above. These analyses revealed that 12 people with MCI showed binding deficits that did not overlap with healthy controls' score, (Figure 1C). Among these MCI patients were those considered MCI+MTA $(\mathrm{n}=10)$. When the ANOVA model was rerun entering solely the data from MCI+MTA, the interaction described above was replicated (Figure 1D). The pattern shows the selectivity of binding deficits previously reported in AD samples (Group x Condition Interaction: $F(1,33)=13.07, p=0.001, \eta 2=0.28 ; \beta=0.94)$.

Insert Figure 1 about here

\section{Discussion}

The present study was carried out to investigate whether and under what condition people with MCI present with the typical pattern of VSTMB impairments consistently found in patients with AD dementia. We were driven by the need of providing evidence of the task's psychometric features that can be clinically friendly as within these setting, procedures such as titration of task difficulty are unfeasible. We also sought evidence of whether VSTMB deficits in MCI are observed in those people who meet criteria for prodromal AD (i.e., significant atrophy of the 
hippocampus as documented by imaging biomarkers). Below we discuss the main implications of our findings.

\section{Why dissecting memory binding impairments is important?}

There are memory functions the decline of which could be detected prior to the dementia stage of AD (e.g., temporary binding abilities). These memory functions have proved both sensitive and specific to AD (Cecchini et al., 2017; S. Della Sala et al., 2012; Parra, Abrahams, Logie, \& Della Sala, 2010). To ascertain whether they are selectively impaired, we need to refine the assessment procedures (R. H. Logie, Parra, \& Della Sala, 2015). Such developments may enable us to map cognitively the continuum of AD. For instance, asymptomatic carriers of the mutation E280APSEN1 leading to familial AD (Parra, Abrahams, Logie, Mendez, et al., 2010) and patients with SCD (Koppara et al., 2015) tested under high memory load (3 items) showed selective memory binding impairments contrasting with a normal neuropsychological background. Without titration and with high memory load, (Koppara et al., 2015) reported that such selectivity disappeared in MCI samples. However, when memory load is low, the selectivity of binding is restored in these MCI people and mirrors that found in patients with AD dementia (Sergio Della Sala et al., 2017).

Here we show, for the first time, that MCI people with evidence of hippocampal atrophy (MCI+MTA) show significant binding deficits when tested under low memory load condition. Interestingly, a subgroup of controls $(\mathrm{n}=7)$ showed performance below a recently reported cut-off (Sergio Della Sala et al., 2017) despite an intact neuropsychological background.

A potential account for these findings could be that under high working memory load $(n=3)$ the reliance on Medial Temporal Lobe structures such as the hippocampus increases (Doherty \& Logie, 2016; Unsworth, Brewer, \& Spillers, 2013), thus rendering the paradigm less specific (i.e., 
performance on both conditions will drop). Recent single case studies of neurological patients with hippocampal damage (Baddeley, Allen, \& Vargha-Khadem, 2010; Jonin et al., 2018; Parra et al., 2015) confirmed that these patients present with preserved STMB even when memory load was higher (3 and 4) than that used with the MCI sample that underwent MRI scans ( $\mathrm{n}=2)$. However, in all cases memory load was below or within the reported capacity of working/short-term memory $(n=4 ;(C o w a n, 2010))$. Future studies with larger samples should investigate if supraspan stimulation engages hippocampal functions and if so, whether such involvement reduces the specificity of the STMBT to dissect binding deficits in samples at risk of AD.

Our results suggest that titration might not be necessary if the task demands are adjusted to and interpreted in line with the different stages of the disease. For example, strategies aimed at screening individuals at risk of $\mathrm{AD}$ (e.g., asymptomatic mutation carriers of APOE4 genotype or other mutations) in whom traditional memory tasks fail (Koppara et al., 2015; Parra, Abrahams, Logie, Mendez, et al., 2010), might capitalise on high memory load while those aimed at screening in more advanced prodromal stages (i.e., $\mathrm{MCI}$ ) or at ascertaining the presence of $\mathrm{AD}$, might focus on lower memory load (Sergio Della Sala et al., 2017; S. Della Sala et al., 2012; Parra, Abrahams, Logie, \& Della Sala, 2010). It is worth noting that reducing memory load to 2 items does not undermine the need of binding (Parra, Della Sala, Logie, \& Morcom, 2014). Hence, use of memory strategies, or lack thereof, should not be the factor explaining the selective binding deficits reported with this paradigm. There are other psychometric properties of the STMBT that grants reliability to this tool for the assessment of AD (R. H. Logie et al., 2015). STMB, as assessed by change detection paradigms, has proved to hold internal consistency (R. Logie, Brockmole, \& Vandenbroucke, 2009). This seems to be a feature of tasks relying on these paradigms (Pailian \& 
Halberda, 2015; Xu, Adam, Fang, \& Vogel, 2018). Moreover, the possibility to adjust the task's demands to the severity of the disease to avoid floor and ceiling effects while retaining construct validly, is another appealing psychometric property of this novel tool. This latter feature makes the task suitable for follow up assessments. However, future studies are still needed to confirm its test-retest and inter-rater reliability.

There might factors other than age and education (see (Koppara et al., 2015; Parra, Abrahams, Logie, \& Della Sala, 2010)) which can lead to poor performance in healthy ageing populations. For instance, in this study, healthy older adults assessed with set size 3 showed a disproportionally large cost of binding compared to that reported in earlier studies (Fernández et al., 2018; Koppara et al., 2015; Parra, Abrahams, Logie, \& Della Sala, 2010). To address this potential limitation a task that combines the two set sizes may be a more feasible approach. Alternatively, as recently suggested by (Sergio Della Sala et al., 2017), a version presenting binding as the only measure drawn from two set sizes could be administered easily and reliably in clinical settings. Older adults with poor VSTMB performance might be those in the very early preclinical stages of AD (see (Parra, Gazes, \& Stern, 2017). these older adults are those experiencing some of

\section{The construct of memory binding in the assessment of $A D$}

A recent review paper summarises developments of neuropsychological approaches for the detection of preclinical AD (Rentz et al., 2013). For example, the FCSRT (Grober, Sanders, Hall, \& Lipton, 2010), has shown promising results (E. Barbeau et al., 2004; E. J. Barbeau et al., 2008; Ivanoiu et al., 2005; Lemos et al., 2016; Sarazin et al., 2007). The Mnemonic Similarity Task (MST), which assesses recognition of common items whose similarity to lures is manipulated, has 
also revealed promising findings (Stark, Yassa, Lacy, \& Stark, 2013). Mnemonic discrimination relies on pattern separation and such a construct also seems to hold marker properties for AD (E. Barbeau et al., 2004; E. J. Barbeau et al., 2008). Performance on such tasks holds the key to understanding memory decline along the continuum of AD (Costa et al., 2017; Sperling et al., 2011). The FCSRT and the MST tax memory functions carried out in LTM. Such functions seem to rely on the hippocampus (Bennett, Huffman, \& Stark, 2015; Sarazin et al., 2010) which for long has been thought of as the earliest target of AD pathology. This view has been recently challenged (Didic et al., 2011). (Papp et al., 2015) used the FCSRT and the Memory Capacity Test (MCT, recently relabelled as the Memory Binding Test - MBT- by (Buschke, 2014)) to assess cognitively normal older adults who show evidence of brain amyloidosis $(\mathrm{A} \beta)$ and neurodegeneration. Zscores computed over the whole sample revealed that the MCT, but not the FCSRT, detected impairment only in advanced stages. Hence, a substantial amount of brain damage needs to accumulate before deficits of LTM binding functions become apparent. However, (Mowrey et al., 2016) recently investigated the predictive validity of the MBT for incident aMCI. They reported that in a longitudinal community-based study of 246 cognitively normal elderly adults aged $70+$ the MBT significantly predicted incident aMCI within a time window ranging from 4 to 7 years. As suggested by (Rentz et al., 2013), more work needs to be done to investigate the added value of these promising test for the preclinical detection of $\mathrm{AD}$. Combining in single assessment protocols memory tests that assess the sub-hippocampal stages of AD ((Didic et al., 2011), e.g., VSTMBT, see also (Wolk, Signoff, \& DeKosky, 2008)) and those sensitive to the hippocampal stages (MBT/MCT/FCSRT, MST, CANTAB-PAL) to map decline of these functions along the AD continuum in larger longitudinal cohorts (see (Costa et al., 2017)), will confirm their value for screening and diagnostic purposes. 


\section{Acknowledgments}

The studies presented here were supproted by Alzheimer's Society Grants AS-R42303 and ASSF-14-008 awared to MAP in collaboration with SDS and SFG. The support from the Alzheimer's

Scotland Dementia Research Centre and the Centre for Cognitive Ageing and Cognitive Epidemiology part of the cross council Lifelong Health and Wellbeing Initiative (MR/K026992/1) both from the University of Edinburgh is also acknowledged. 
(A)

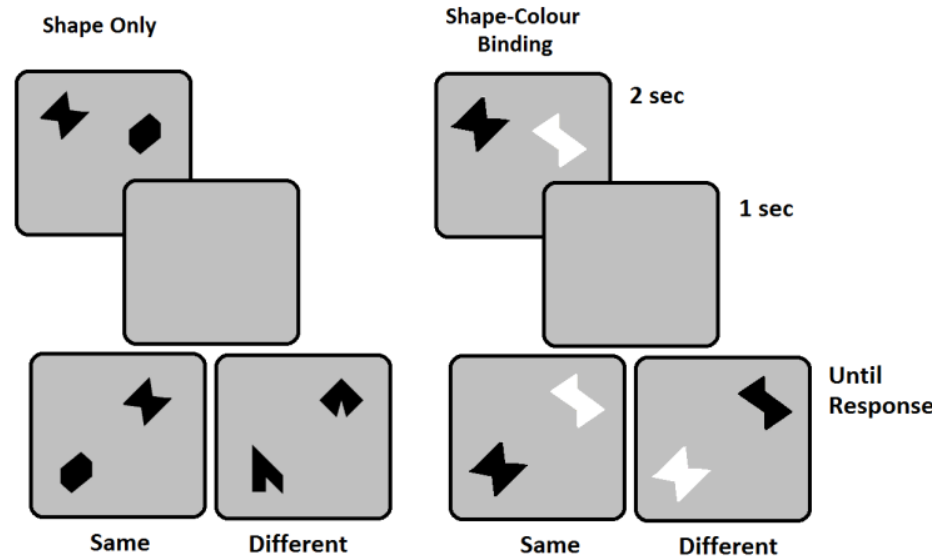

(C)

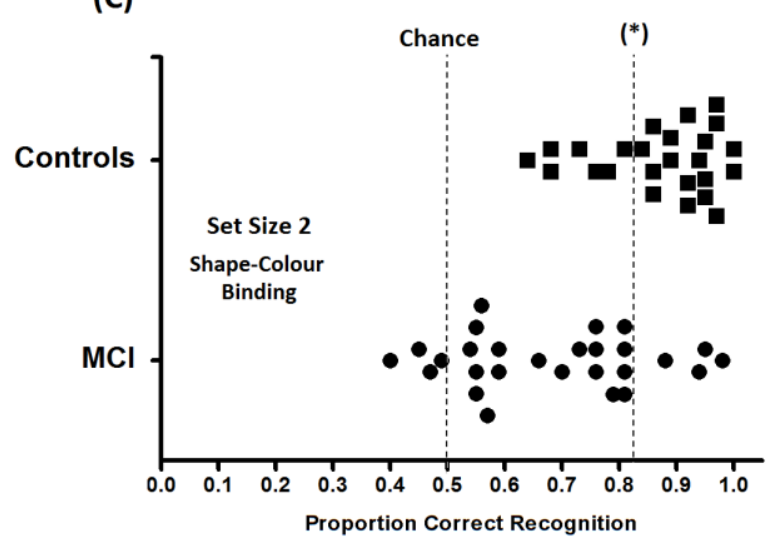

(B)

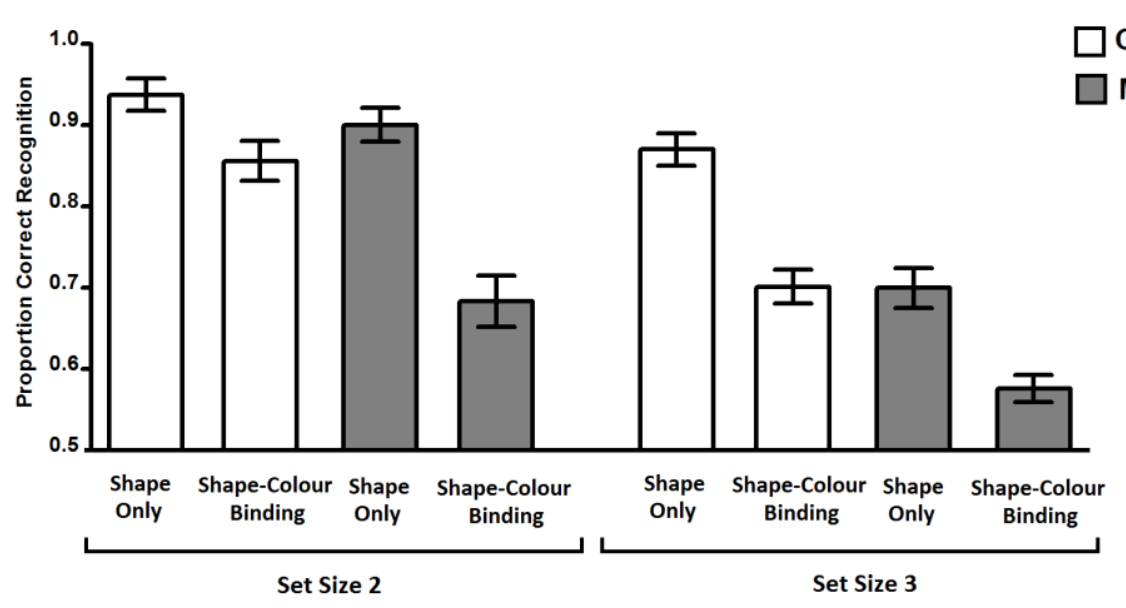

$\square$ Controls

$\square \mathrm{MCl}$

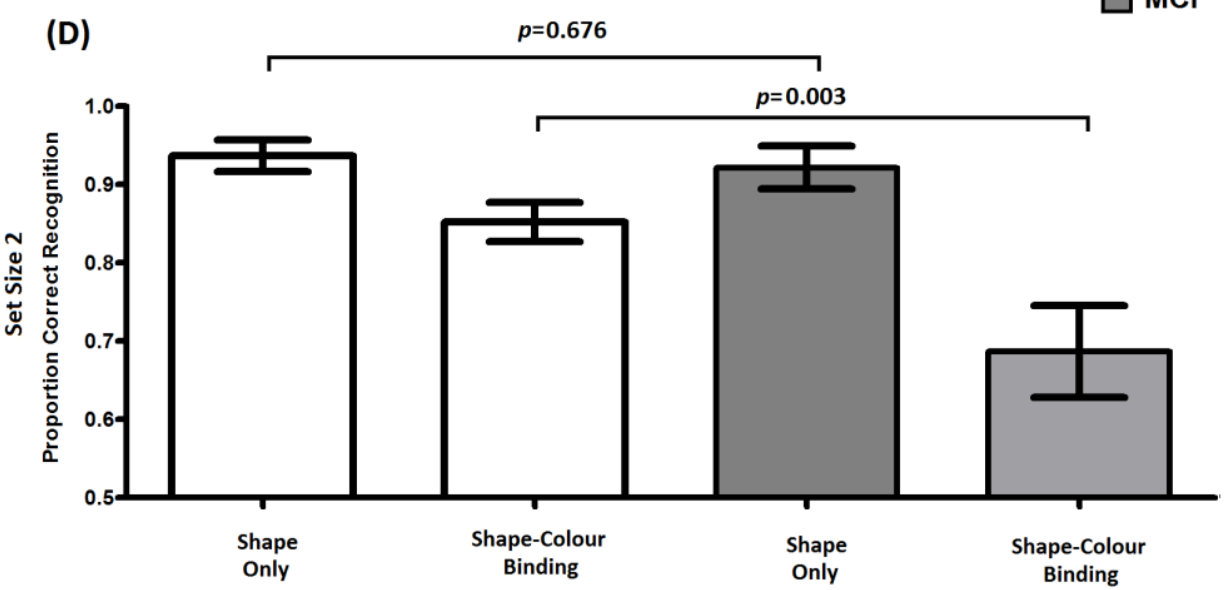

Figure 1. (A) An example trial for each condition of the Short-Term Memory Binding Test using Set Size 2. (B) Mean data from the Short-Term Memory Binding Test (error bars = SEM). (C) Overlap between people with Mild Cognitive Impairment $(\mathrm{MCI})$ and Controls in the Shape-Colour 
Binding condition of the Short-Term Memory Binding Test using Set Size 2. Twelve MCI people did not overlap with controls and fell below the cut-off $(*)$ recently reported by (Sergio Della Sala et al., 2017) There were 7 controls whose score were also below such a cut-off. Their neuropsychological background and that from controls above cut-off did not significantly differ (see Supplementary Table 1). (D) Mean data from the Short-Term Memory Binding Test from Controls and the 10 MCI people who had MRI evidence of hippocampal atrophy. 
Table 1. Demographic, clinical and neuropsychological variables of subjects tested with the two set sizes.

\begin{tabular}{|c|c|c|c|c|c|c|c|c|c|c|c|c|c|c|}
\hline & \multicolumn{4}{|c|}{ Set Size 2} & \multicolumn{4}{|c|}{ Set Size 3} & \multirow{2}{*}{\multicolumn{2}{|c|}{ ANOVA }} & \multicolumn{4}{|c|}{ Post-Hoc } \\
\hline & \multicolumn{2}{|c|}{ Controls $(n=25)$} & \multicolumn{2}{|c|}{$\operatorname{MCI}(n=27)$} & \multicolumn{2}{|c|}{ Controls $(n=29)$} & \multicolumn{2}{|c|}{$\operatorname{MCI}(n=23)$} & & & SS2 & SS3 & Ctr & MCI \\
\hline & Mean (SD) & Range & Mean (SD) & Range & Mean (SD) & Range & Mean (SD) & Range & $\boldsymbol{F}$ & $p$ & MCI & MCI & SS3 & SS3 \\
\hline Age & $74.73(4.74)$ & $(66.00-83.00)$ & $75.07(5.30)$ & $(65.00-87.00)$ & $72.34(3.76)$ & $(68.00-80.00)$ & $75.43(5.77)$ & $(67.00-86.00)$ & 2.25 & 0.087 & 1.000 & 0.157 & 0.449 & 1.000 \\
\hline Education & $10.84(5.02)$ & $(4.00-16.00)$ & $10.86(5.80)$ & $(4.00-20.00)$ & $11.00(5.11)$ & $(0.00-20.00)$ & $9.43(2.90)$ & $(6.00-15.00)$ & 0.54 & 0.655 & 1.000 & 1.000 & 1.000 & 1.000 \\
\hline GDS & $1.12(1.96)$ & $(0.00-7.00)$ & $2.00(2.21)$ & $(0.00-7.00)$ & $1.28(2.02)$ & $(0.00-9.00)$ & $2.39(1.90)$ & $(0.00-7.00)$ & 2.19 & 0.094 & 0.684 & 0.316 & 1.000 & 1.000 \\
\hline MMSE & $27.52(1.98)$ & $(24.00-30.00)$ & $23.90(2.88)$ & $(20.00-29.00)$ & $28.90(1.23)$ & $(26.00-30.00)$ & $25.22(1.73)$ & $(20.00-27.00)$ & 33.42 & * & 0.001 & $*$ & 0.101 & 0.144 \\
\hline Blessed Scale & $0.40(0.76)$ & $(0.00-2.50)$ & $3.05(2.62)$ & $(0.00-10.00)$ & $1.23(1.54)$ & $(0.00-7.00)$ & $3.41(3.02)$ & $(0.00-12.00)$ & 11.31 & $*$ & $*$ & 0.004 & 0.979 & 1.000 \\
\hline TAVEC Imm Free Recall & $9.61(3.34)$ & $(0.00-14.00)$ & $4.50(3.70)$ & $(0.00-13.00)$ & $10.52(2.37)$ & $(7.00-16.00)$ & $4.52(4.04)$ & $(0.00-14.00)$ & 24.25 & $*$ & $*$ & $*$ & 1.000 & 1.000 \\
\hline TAVEC Imm Cued Recall & $11.21(2.11)$ & $(7.00-15.00)$ & $6.17(3.36)$ & $(0.00-13.00)$ & $11.97(2.28)$ & $(5.00-16.00)$ & $6.74(3.54)$ & $(1.00-14.00)$ & 29.17 & $*$ & $*$ & $*$ & 1.000 & 1.000 \\
\hline TAVEC Delayed Free Recall & $10.13(2.97)$ & $(0.00-14.00)$ & $4.37(3.64)$ & $(0.00-13.00)$ & $11.31(1.97)$ & $(9.00-16.00)$ & $4.70(3.73)$ & $(0.00-14.00)$ & 35.93 & $*$ & $*$ & $*$ & 1.000 & 1.000 \\
\hline TAVEC Delayed Cued Recall & $11.00(1.96)$ & $(7.00-16.00)$ & $6.73(3.68)$ & $(0.00-15.00)$ & $12.17(2.24)$ & $(7.00-16.00)$ & $6.13(3.17)$ & $(1.00-12.00)$ & 29.57 & * & $*$ & $*$ & 0.852 & 1.000 \\
\hline TAVEC Recognition & $14.58(1.59)$ & $(11.00-16.0)$ & $14.07(1.89)$ & $(9.00-16.00)$ & $14.76(1.41)$ & $(12.00-16.00)$ & $13.74(2.09)$ & $(9.00-16.00)$ & 1.83 & 0.146 & 1.000 & 0.239 & 1.000 & 1.000 \\
\hline TMT-A & $58.76(21.58)$ & $(23.00-116.0)$ & $95.80(56.19)$ & $(31.00-260.00)$ & $55.59(16.06)$ & $(26.00-97.00)$ & $116.48(79.33)$ & $(32.00-357.0)$ & 9.21 & $*$ & 0.038 & $*$ & 1.000 & 0.791 \\
\hline TMT-B & $167.64(93.0)$ & $(49.00-360.0)$ & $298.93(150.86)$ & $(117.00-673.0)$ & $156.34(76.51)$ & $(74.00-443.0)$ & 381.23 (231.44) & $(80.00-929.0)$ & 13.69 & $*$ & 0.008 & $*$ & 1.000 & 0.297 \\
\hline ROF Copy & $28.56(7.39)$ & $(8.00-36.00)$ & $22.92(9.20)$ & $(6.50-36.00)$ & $33.69(2.88)$ & $(25.00-36.00)$ & $28.54(8.10)$ & $(2.50-36.00)$ & 10.83 & * & 0.033 & 0.076 & 0.072 & 0.037 \\
\hline ROF Imm Recall & $12.48(6.72)$ & $(2.00-29.00)$ & $7.79(7.06)$ & $(0.00-30.00)$ & $16.50(6.00)$ & $(6.00-28.00)$ & $7.22(4.97)$ & $(0.00-17.00)$ & 13.14 & $*$ & 0.053 & $*$ & 0.143 & 1.000 \\
\hline ROF Delayed Recall & $11.23(6.27)$ & $(2.05-26.50)$ & $7.02(7.04)$ & $(0.00-28.00)$ & $16.60(6.15)$ & $(3.00-28.00)$ & $6.80(4.74)$ & $(0.00-18.00)$ & 15.39 & $*$ & 0.105 & $*$ & 0.016 & 1.000 \\
\hline Letter Fluency (FAS) & $34.92(12.12)$ & $(13.00-61.00)$ & $24.03(8.47)$ & $(11.00-42.00)$ & $35.24(9.53)$ & $(14.00-54.00)$ & $27.82(10.01)$ & $(11.00-51.00)$ & 8.43 & $*$ & 0.001 & 0.060 & 1.000 & 1.000 \\
\hline Semantic Fluency & $61.82(11.30)$ & $(37.00-81.00)$ & $48.87(11.53)$ & $(24.00-80.00)$ & $59.79(9.44)$ & $(45.00-76.00)$ & $43.45(10.95)$ & $(22.00-60.00)$ & 15.82 & $*$ & $*$ & * & 1.000 & 0.463 \\
\hline VSTM Shape Only & $0.94(0.10)$ & $(0.57-1.00)$ & $0.90(0.11)$ & $(0.52-1.00)$ & $0.87(0.11)$ & $(0.53-1.00)$ & $0.70(0.12)$ & $(0.53-0.94)$ & 22.37 & $*$ & 1.000 & $*$ & 0.150 & * \\
\hline VSTM Shape-Colour Binding & $0.86(0.12)$ & $(0.51-1.00)$ & $0.68(0.16)$ & $(0.40-0.98)$ & $0.70(0.11)$ & $(0.53-0.97)$ & $0.58(0.08)$ & $(0.41-0.75)$ & 21.01 & $*$ & $*$ & 0.003 & $*$ & 0.018 \\
\hline
\end{tabular}

$* p<0.001$; Blessed Scale (Blessed, Tomlinson, \& Roth, 1968); GDS: Geriatric Depression Scale (Yesavage et al., 1982); Imm: Immediate Recall;

MMSE: Mini Mental State Examination (Folstein, Folstein, \& McHugh, 1975); SS2 \& 3: Set Sizes 2 and 3; TAVEC: Spanish version of the California

Verbal Learning Test (Delis, Kramer, Kaplan, \& Ober, 1987). 


\section{References}

Amariglio, R. E., Frishe, K., Olson, L. E., Wadsworth, L. P., Lorius, N., Sperling, R. A., \& Rentz, D. M. (2012). Validation of the Face Name Associative Memory Exam in cognitively normal older individuals. J Clin Exp. Neuropsychol, 34(6), 580-587. Retrieved from http://www.ncbi.nlm.nih.gov/pubmed/22765048. doi:10.1080/13803395.2012.666230 [doi]

Auriacombe, S., Helmer, C., Amieva, H., Berr, C., Dubois, B., \& Dartigues, J. F. (2010). Validity of the free and cued selective reminding test in predicting dementia: the $3 \mathrm{C}$ study. Neurology, 74(22), 1760-1767. Retrieved from http://www.ncbi.nlm.nih.gov/pubmed/20410465. doi:WNL.0b013e3181df0959 [pii];10.1212/WNL.0b013e3181df0959 [doi]

Baddeley, A., Allen, R., \& Vargha-Khadem, F. (2010). Is the hippocampus necessary for visual and verbal binding in working memory? Neuropsychologia, 48(4), 1089-1095. Retrieved from http://www.ncbi.nlm.nih.gov/pubmed/20006631.

Barbeau, E., Didic, M., Tramoni, E., Felician, O., Joubert, S., Sontheimer, A., . . Poncet, M. (2004). Evaluation of visual recognition memory in MCI patients. Neurology. 62(8):1317-22,

Barbeau, E. J., Ranjeva, J. P., Didic, M., Confort-Gouny, S., Felician, O., Soulier, E., . . . Poncet, M. (2008). Profile of memory impairment and gray matter loss in amnestic mild cognitive impairment. Neuropsychologia, 46(4), 1009-1019. Retrieved from http://www.ncbi.nlm.nih.gov/pubmed/18191160. doi:S0028-3932(07)00387-9 [pii];10.1016/j.neuropsychologia.2007.11.019 [doi]

Bennett, I. J., Huffman, D. J., \& Stark, C. E. (2015). Limbic Tract Integrity Contributes to Pattern Separation Performance Across the Lifespan. Cereb. Cortex, 25(9), 2988-2999. Retrieved from http://www.ncbi.nlm.nih.gov/pubmed/24825784. doi:cercor/bhu093 [pii];10.1093/cercor/bhu093 [doi]

Blessed, G., Tomlinson, B. E., \& Roth, M. (1968). The association between quantitative measures of dementia and of senile change in the cerebral grey matter of elderly subjects. $\mathrm{Br} J$ Psychiatry, 114(512), 797-811. Retrieved from http://www.ncbi.nlm.nih.gov/pubmed/5662937.

Buschke, H. (2014). Rationale of the memory binding test. In L. Nilsson \& H. Ohta (Eds.), Dementia and Memory (First ed., pp. 55-71). East Sussex: Psychology Press. (Reprinted from: Not in File).

Cecchini, M. A., Yassuda, M. S., Bahia, V. S., de Souza, L. C., Guimaraes, H. C., Caramelli, P., . . . Parra, M. A. (2017). Recalling feature bindings differentiates Alzheimer's disease from frontotemporal dementia. $J$ Neurol, 264(10), 2162-2169. doi:10.1007/s00415-017-8614-9

Chalfonte, B. L., Verfaellie, M., Johnson, M. K., \& Reiss, L. (1996). Spatial location memory in amnesia: binding item and location information under incidental and intentional encoding conditions. Memory, 4(6), 591-614. Retrieved from http://www.ncbi.nlm.nih.gov/pubmed/8934456.

Costa, A., Bak, T., Caffarra, P., Caltagirone, C., Ceccaldi, M., Collette, F., . . . Cappa, S. F. (2017). The need for harmonisation and innovation of neuropsychological assessment in neurodegenerative dementias in Europe: consensus document of the Joint Program for Neurodegenerative Diseases Working Group. Alzheimers. Res. Ther, 9(1), 27. Retrieved from http://www.ncbi.nlm.nih.gov/pubmed/28412978. doi:10.1186/s13195017-0254-x [doi];10.1186/s13195-017-0254-x [pii] 
Cowan, N. (2010). The Magical Mystery Four: How is Working Memory Capacity Limited, and Why? Curr. Dir. Psychol. Sci, 19(1), 51-57. Retrieved from http://www.ncbi.nlm.nih.gov/pubmed/20445769. doi:10.1177/0963721409359277 [doi]

Delis, D. C., Kramer, J. H., Kaplan, E., \& Ober, B. A. (1987). California verbal learning test: Form II. San Antonio: Psychological Corporation.

Della Sala, S., Data, L., Stamate, A., \& Parra, M. A. (2017). A transcultural cognitive marker of Alzheimer's Disease. International Journal of Geriatric Psychiatry, n/a-n/a. Retrieved from http://dx.doi.org/10.1002/gps.4610.

Della Sala, S., Parra, M. A., Fabi, K., Luzzi, S., \& Abrahams, S. (2012). Short-term memory binding is impaired in AD but not in non-AD dementias. Neuropsychologia, 50, 833840. doi:http://dx.doi.org/10.1016/j.neuropsychologia.2012.01.018

Didic, M., Barbeau, E. J., Felician, O., Tramoni, E., Guedj, E., Poncet, M., \& Ceccaldi, M. (2011). Which memory system is impaired first in Alzheimer's disease? J Alzheimers Dis, 27(1), 11-22.

Doherty, J. M., \& Logie, R. H. (2016). Resource-sharing in multiple-component working memory. Memory \& Cognition, 44(8), 1157-1167. Retrieved from http://dx.doi.org/10.3758/s13421-016-0626-7.

Dubois, B., Feldman, H. H., Jacova, C., Cummings, J. L., DeKosky, S. T., Barberger-Gateau, P., . . . Scheltens, P. (2010). Revising the definition of Alzheimer's disease: a new lexicon. Lancet Neurol, 9(11), 1118-1127. Retrieved from http://www.ncbi.nlm.nih.gov/pubmed/20934914. doi:S1474-4422(10)70223-4 [pii];10.1016/S1474-4422(10)70223-4 [doi]

Dubois, B., Hampel, H., Feldman, H. H., Scheltens, P., Aisen, P., Andrieu, S., . . Jack, C. R., Jr. (2016). Preclinical Alzheimer's disease: Definition, natural history, and diagnostic criteria. Alzheimers. Dement, 12(3), 292-323. Retrieved from http://www.ncbi.nlm.nih.gov/pubmed/27012484. doi:S1552-5260(16)00050-9 [pii];10.1016/j.jalz.2016.02.002 [doi]

Fernández, G., Orozco, D., Agamennoni, O., Schumacher, M., Sañudo, S., Biondi, J., \& Parra, M. A. (2018). Visual processing during short-term memory binding in mild Alzheimer's disease. Journal of Alzheimer's Disease, (in press).

Fields, J. A., Ferman, T. J., Boeve, B. F., \& Smith, G. E. (2011). Neuropsychological assessment of patients with dementing illness. Nat. Rev. Neurol, 7(12), 677-687. Retrieved from http://www.ncbi.nlm.nih.gov/pubmed/22045270. doi:nrneurol.2011.173 [pii];10.1038/nrneurol.2011.173 [doi]

Fischl, B., Salat, D. H., Busa, E., Albert, M., Dieterich, M., Haselgrove, C., . . . Dale, A. M. (2002). Whole Brain Segmentation: Automated Labeling of Neuroanatomical Structures in the Human Brain. Neuron, 33(3), 341-355. Retrieved from http://www.sciencedirect.com/science/article/pii/S089662730200569X. doi:https://doi.org/10.1016/S0896-6273(02)00569-X

Folstein, M. F., Folstein, S. E., \& McHugh, P. R. (1975). "Mini-mental state". A practical method for grading the cognitive state of patients for the clinician. J Psychiatr Res, 12(3), 189-198.

Gallo, D. A., Sullivan, A. L., Daffner, K. R., Schacter, D. L., \& Budson, A. E. (2004). Associative recognition in Alzheimer's disease: evidence for impaired recall-to-reject. Neuropsychology, 18(3), 556-563. Retrieved from http://www.ncbi.nlm.nih.gov/pubmed/15291733.

Grober, E., Buschke, H., Crystal, H., Bang, S., \& Dresner, R. (1988). Screening for dementia by memory testing. Neurology, 38(6), 900-903. Retrieved from http://www.ncbi.nlm.nih.gov/pubmed/3368071. 
Grober, E., Sanders, A. E., Hall, C., \& Lipton, R. B. (2010). Free and cued selective reminding identifies very mild dementia in primary care. Alzheimer Disease and Associated Disorders, 24(3), 284-290. Retrieved from http://ukpmc.ac.uk/abstract/MED/20683186.

Ivanoiu, A., Adam, S., Van der, L. M., Salmon, E., Juillerat, A. C., Mulligan, R., \& Seron, X. (2005). Memory evaluation with a new cued recall test in patients with mild cognitive impairment and Alzheimer's disease. J Neurol, 252(1), 47-55. Retrieved from http://www.ncbi.nlm.nih.gov/pubmed/15654553.

Jack, C. R., Jr., Petersen, R. C., Xu, Y. C., Waring, S. C., O'Brien, P. C., Tangalos, E. G., .. . Kokmen, E. (1997). Medial temporal atrophy on MRI in normal aging and very mild Alzheimer's disease.[see comment]. Neurology. 49(3):786-94,.

Jonin, P.-Y., Calia, C., Muratot, S., Belliard, S., Duche, Q., Barbeau, E. J., \& Parra, M. A. (2018). Refining understanding of working memory buffers through the construct of binding: Evidence from a single case informs theory and clinical practise. Cortex. Retrieved from http://www.sciencedirect.com/science/article/pii/S0010945218302612. doi:https://doi.org/10.1016/j.cortex.2018.08.011

Koppara, A., Frommann, I., Polcher, A., Parra, M. A., Maier, W., Jessen, F., . . Wagner, M. (2015). Feature Binding Deficits in Subjective Cognitive Decline and in Mild Cognitive Impairment. $J$ Alzheimers. Dis, 48 Suppl 1, S161-S170. Retrieved from http://www.ncbi.nlm.nih.gov/pubmed/26402080. doi:JAD150105 [pii];10.3233/JAD150105 [doi]

Lemos, R., Afonso, A., Martins, C., Waters, J. H., Blanco, F. S., Simoes, M. R., \& Santana, I. (2016). Selective Reminding and Free and Cued Selective Reminding in Mild Cognitive Impairment and Alzheimer Disease. Appl. Neuropsychol Adult, 23(2), 85-93. Retrieved from http://www.ncbi.nlm.nih.gov/pubmed/26375308. doi:10.1080/23279095.2015.1012761 [doi]

Logie, R., Brockmole, J. R., \& Vandenbroucke, A. R. E. (2009). Bound Feature Combinations in Visual Short Term Memory are Fragile but Influence Long-Term Learning. Visual Cognition, 17(1/2), 160-179.

Logie, R. H., Parra, M. A., \& Della Sala, S. (2015). From Cognitive Science to Dementia Assessment. Policy Insights from the Behavioral and Brain Sciences, 2(1), 81-91. Retrieved from http://bbs.sagepub.com/content/2/1/81.abstract.

Luck, S. J., \& Vogel, E. K. (1997). The capacity of visual working memory for features and conjunctions. Nature, 390(6657), 279-281. Retrieved from http://www.ncbi.nlm.nih.gov/pubmed/9384378.

Mowrey, W. B., Lipton, R. B., Katz, M. J., Ramratan, W. S., Loewenstein, D. A., Zimmerman, M. E., \& Buschke, H. (2016). Memory Binding Test Predicts Incident Amnestic Mild Cognitive Impairment. J Alzheimers Dis, 53(4), 1585-1595. doi:10.3233/jad-160291

Olazaran, J., Hernandez-Tamames, J. A., Molina, E., Garcia-Polo, P., Dobato, J. L., AlvarezLinera, J., \& Martinez-Martin, P. (2013). Clinical and anatomical correlates of gait dysfunction in Alzheimer's disease. J. Alzheimers. Dis, 33(2), 495-505. Retrieved from http://www.ncbi.nlm.nih.gov/pubmed/23011219.

doi:JU81U3354KQ1M348 [pii];10.3233/JAD-2012-121207 [doi]

Old, S. R., \& Naveh-Benjamin, M. (2008). Differential effects of age on item and associative measures of memory: a meta-analysis. Psychol Aging, 23(1), 104-118. Retrieved from http://www.ncbi.nlm.nih.gov/pubmed/18361660.

Pailian, H., \& Halberda, J. (2015). The reliability and internal consistency of one-shot and flicker change detection for measuring individual differences in visual working memory capacity. Mem Cognit, 43(3), 397-420. doi:10.3758/s13421-014-0492-0 
Papp, K. V., Amariglio, R. E., Mormino, E., Hedden, T., Dekhytar, M., Johnson, K. A., . . . Rentz, D. M. (2015). Free and cued memory in relation to biomarker-defined Abnormalities in clinically normal older Adults and those at risk for Alzheimer's disease. Neuropsychologia. Retrieved from http://www.ncbi.nlm.nih.gov/pubmed/26002757. doi:S0028-3932(15)30011-7 [pii];10.1016/j.neuropsychologia.2015.04.034 [doi]

Parra, M. A., Abrahams, S., Fabi, K., Logie, R., Luzzi, S., \& Della Sala, S. (2009). Short-term memory binding deficits in Alzheimer's disease. Brain, 132(Pt 4), 1057-1066. Retrieved from http://www.ncbi.nlm.nih.gov/pubmed/19293236. doi:awp036 [pii];10.1093/brain/awp036 [doi]

Parra, M. A., Abrahams, S., Logie, R. H., \& Della Sala, S. (2010). Visual short-term memory binding in Alzheimer's disease and depression. J. Neurol, 257(7), 1160-1169. Retrieved from http://www.ncbi.nlm.nih.gov/pubmed/20162428. doi:10.1007/s00415-010-54849 [doi]

Parra, M. A., Abrahams, S., Logie, R. H., Mendez, L. G., Lopera, F., \& Della Sala, S. (2010). Visual short-term memory binding deficits in familial Alzheimer's disease. Brain, 133(9), 2702-2713. Retrieved from http://www.ncbi.nlm.nih.gov/pubmed/20624814. doi:awq148 [pii];10.1093/brain/awq148 [doi]

Parra, M. A., Della Sala, S., Abrahams, S., Logie, R. H., Mendez, L. G., \& Lopera, F. (2011). Specific deficit of colour-colour short-term memory binding in sporadic and familial Alzheimer's disease. Neuropsychologia, 49(7), 1943-1952. Retrieved from http://www.ncbi.nlm.nih.gov/pubmed/21435348. doi:S0028-3932(11)00154-0 [pii];10.1016/j.neuropsychologia.2011.03.022 [doi]

Parra, M. A., Della Sala, S., Logie, R. H., \& Morcom, A. M. (2014). Neural correlates of shapecolor binding in visual working memory. Neuropsychologia, 52(0), 27-36. Retrieved from http://www.sciencedirect.com/science/article/pii/S0028393213003382.

Parra, M. A., Fabi, K., Luzzi, S., Cubelli, R., Hernandez, V. M., \& Della, S. S. (2015). Relational and conjunctive binding functions dissociate in short-term memory. Neurocase, 21(1), 56-66. Retrieved from http://www.ncbi.nlm.nih.gov/pubmed/24313316. doi:10.1080/13554794.2013.860177 [doi]

Parra, M. A., Gazes, Y., \& Stern, Y. (2017). From cognition to molecules: tracking brain amyloid-Beta with memory markers for Alzheimer's disease. Alzheimer's \& Dementia: The Journal of the Alzheimer's Association, 13(7), P692. Retrieved from http://dx.doi.org/10.1016/j.jalz.2017.06.866. doi:10.1016/j.jalz.2017.06.866

Petersen, R. C. (2004). Mild cognitive impairment as a diagnostic entity. J. Intern. Med, 256(3), 183-194. Retrieved from http://www.ncbi.nlm.nih.gov/pubmed/15324362.

Rentz, D., Parra, M. A., Amariglio, R., Stern, Y., Sperling, R., \& Ferris, S. (2013). Promising developments in neuropsychological approaches for the detection of preclinical Alzheimer's disease: a selective review. Alzheimer's Research \& Therapy, 5(6), 58. Retrieved from http://alzres.com/content/5/6/58. doi:10.1186/alzrt222

Sahakian, B. J., Morris, R. G., Evenden, J. L., Heald, A., Levy, R., Philpot, M., \& Robbins, T. W. (1988). A comparative study of visuospatial memory and learning in Alzheimertype dementia and Parkinson's disease. Brain. 111 ( Pt 3):695-718,.

Sarazin, M., Berr, C., De, R. J., Fabrigoule, C., Pasquier, F., Legrain, S., . . Dubois, B. (2007). Amnestic syndrome of the medial temporal type identifies prodromal AD: a longitudinal study. Neurology, 69(19), 1859-1867. Retrieved from http://www.ncbi.nlm.nih.gov/pubmed/17984454.

Sarazin, M., Chauvire, V., Gerardin, E., Colliot, O., Kinkingnehun, S., de Souza, L. C., . . . Dubois, B. (2010). The amnestic syndrome of hippocampal type in Alzheimer's disease: 
an MRI study. $J$ Alzheimers Dis, 22(1), 285-294. Retrieved from http://www.ncbi.nlm.nih.gov/pubmed/20847406.

doi:08G11707184805J4 [pii];10.3233/JAD-2010-091150 [doi]

Sperling, R. A., Aisen, P. S., Beckett, L. A., Bennett, D. A., Craft, S., Fagan, A. M., . . Phelps, C. H. (2011). Toward defining the preclinical stages of Alzheimer's disease: recommendations from the National Institute on Aging-Alzheimer's Association workgroups on diagnostic guidelines for Alzheimer's disease. Alzheimers. Dement, 7(3), 280-292. Retrieved from http://www.ncbi.nlm.nih.gov/pubmed/21514248. doi:S1552-5260(11)00099-9 [pii];10.1016/j.jalz.2011.03.003 [doi]

Sperling, R. A., Bates, J. F., Chua, E. F., Cocchiarella, A. J., Rentz, D. M., Rosen, B. R., . . . Albert, M. S. (2003). fMRI studies of associative encoding in young and elderly controls and mild Alzheimer's disease. Journal of Neurology, Neurosurgery and Psychiatry, 74(1), 44-50. Retrieved from http://www.ncbi.nlm.nih.gov/pubmed/12486265.

Stark, S. M., Yassa, M. A., Lacy, J. W., \& Stark, C. E. L. (2013). A task to assess behavioral pattern separation (BPS) in humans: Data from healthy aging and mild cognitive impairment. Paper presented at the Neuropsychologia

Special Issue on Functional Neuroimaging of Episodic Memory. http://www.sciencedirect.com/science/article/pii/S002839321300002X

Stehli, N. A., Chubb, C., \& Jacob, H. F. (2003). Visual identification and spatial location in Alzheimer's disease. Brain \& Cognition. 52(2):155-66,

Tulving, E. (2002). Episodic memory: from mind to brain. Annual Review of Psychology, 53, 1-25. Retrieved from http://www.ncbi.nlm.nih.gov/pubmed/11752477.

Unsworth, N., Brewer, G. A., \& Spillers, G. J. (2013). Working memory capacity and retrieval from long-term memory: the role of controlled search. Mem. Cognit, 41(2), 242-254. Retrieved from http://www.ncbi.nlm.nih.gov/pubmed/23055120. doi:10.3758/s13421012-0261-x [doi]

Vogel, E. K., Woodman, G. F., \& Luck, S. J. (2001). Storage of features, conjunctions and objects in visual working memory. J. Exp. Psychol. Hum. Percept. Perform, 27(1), 92114. Retrieved from http://www.ncbi.nlm.nih.gov/pubmed/11248943.

Wolk, D. A., Signoff, E. D., \& DeKosky, S. T. (2008). Recollection and familiarity in amnestic mild cognitive impairment: a global decline in recognition memory. Neuropsychologia, 46(7), 1965-1978. Retrieved from http://www.ncbi.nlm.nih.gov/pubmed/18328509. doi:S0028-3932(08)00052-3 [pii];10.1016/j.neuropsychologia.2008.01.017 [doi]

Xu, Z., Adam, K. C. S., Fang, X., \& Vogel, E. K. (2018). The reliability and stability of visual working memory capacity. Behav Res Methods, 50(2), 576-588. doi:10.3758/s13428017-0886-6

Yesavage, J. A., Brink, T. L., Rose, T. L., Lum, O., Huang, V., Adey, M., \& Leirer, V. O. (1982). Development and validation of a geriatric depression screening scale: a preliminary report. $J$ Psychiatr. Res, 17(1), 37-49. Retrieved from http://www.ncbi.nlm.nih.gov/pubmed/7183759. 